\title{
EVALUATION OF ONION DOWNY MILDEW DISEASE RISK IN NEW ZEALAND USING METEOROLOGICAL FORECASTING CRITERIA
}

\author{
S.A. WHITEMAN and R.M. BERESFORD
}

\author{
The Horticulture and Food Research Institute of New Zealand Ltd. \\ Mt. Albert Research Centre, Private Bag 92-169, Auckland
}

\begin{abstract}
Meteorological prediction criteria for onion downy mildew (Peronospora destructor), adapted from the disease forecasting system "Downcast", were used to examine patterns of disease risk in two climatically contrasted New Zealand onion growing regions. Potential sporulation and infection events were predicted to occur in both regions in all months between September and April, although South Auckland had more events (27-43\% of days per month) than Canterbury (10-18\% of days per month). Predicted disease risk was most often limited in Canterbury when relative humidity failed to reach the level required for sporulation. In South Auckland, risk was most often limited by insufficient leaf wetness duration for infection, but in one low rainfall year, relative humidity was the most often limiting factor, as in Canterbury. It appears that in Canterbury, and in some seasons in South Auckland, forecasting criteria could be used to modify fungicide timing for downy mildew control.
\end{abstract}

Keywords: Onion downy mildew, Peronospora destructor, disease prediction, weather.

\section{INTRODUCTION}

Without the use of fungicides, economic onion production would not be possible in New Zealand because of crop losses caused by various diseases. Downy mildew (Peronospora destructor) is the target disease for most of the fungicides applied to onions, and typically requires 12-14 applications per season. The onion industry is under pressure to reduce reliance on chemicals and therefore new management approaches that could reduce numbers of fungicide applications against downy mildew would be of great benefit.

The use of weather-based disease forecasting may offer a means to reduce reliance on fungicides without increasing the risk of disease control failure. A Canadian forecasting system, "Downcast" (Jesperson and Sutton 1987), summarizes weather conditions that allow the infection cycle of $P$. destructor to proceed. Five meteorological criteria identify when conditions are suitable for sporulation of the fungus and for subsequent infection of leaves by deposited spores (sporulation-infection events). It is claimed that the system allows curative fungicides to be applied immediately after sporulation-infection events, effectively eliminating infection which has just occurred (Hildebrand and Sutton 1982).

This paper reports the adaptation of the "Downcast" criteria for use with historical weather data from two climatically contrasted New Zealand onion growing regions. Annual and regional variations in calculated disease risk were examined to identify the potential that exists to modify fungicide use.

\section{Disease risk criteria}

\section{MATERIALS AND METHODS}

Sporulation requires high relative humidity $(\mathrm{RH})$, but not rain, in the early hours of the morning. Germination of spores and penetration of the leaf requires leaf 
wetness, either immediately following sporulation, or the following night. Requirements for sporulation and infection for this study were defined as follows (hours given are data logger output times which summarize the previous hour):

Sporulation:

1) Mean temperature between 0800 and 2000 (NZST) during the previous day $\leq 24^{\circ} \mathrm{C}$.

2) Mean hourly temperature at night (2000-0500) between $4^{\circ} \mathrm{C}$ and $24^{\circ} \mathrm{C}$.

3) No rain between 0100 and 0500 (total rain $<0.2 \mathrm{~mm}$ ).

4) Relative humidity (RH) continuously $\geq 95 \%$ between 0100 and 0500.

Infection by deposited spores:

either:

1) Leaf surface wetness (mean hourly sensor output $\geq 50 \%$ ) for the four hours ending 0500 to 0800 (i.e. meeting or exceeding a total of 200 wetness units). or:

2) Infection occurs the following evening if the leaf surface remains wet for three hours between 1900 and 2400 (i.e. a total $\geq 150$ wetness units).

Sporulation-infection events were identified within the meteorological records using Microsoft Excel 6.0 spreadsheets with Logic Function Analysis.

\section{Differences from "Downcast"}

The time for the pre-dawn high $\mathrm{RH} /$ no rain period required for sporulation was altered from 0200-0600 in "Downcast" to 0100-0500, to allow for New Zealand sunrise times. "Downcast" allows infection to take place during the same night that sporulation criteria have been met, but if the period of wetness is not long enough, the spores can infect on a second or third night. To simplify computation we allowed for infection to occur on a second but not a third night. Hildebrand and Sutton (1984b) found that whereas "rapid" dew deposition led to infection and no dew allowed spore survival, "slow" dew deposition could lead to death of spores without infection. No attempt was made to distinguish between dew types because of the difficulty in interpreting what "rapid" and "slow" might represent with the different type of wetness sensor used in this study.

\section{Historical weather records}

Weather data from September-April were examined. This period included one month before the earliest date downy mildew is likely to appear in onion crops and about the time fungicide use stops in late-harvest onions in New Zealand. Three seasons' records were available from Pukekohe in South Auckland (1993-94, 1995-96 and 1996-97) and five seasons' records for Lincoln, Canterbury (1992-93 to 1996-97). All data were collected using Campbell Scientific Instruments CR10 data loggers with Model 107 thermistor probes and Model 237 surface wetness sensors. Wet and dry bulb temperatures (air temperature and relative humidity) were measured in thermometer screens $1.5 \mathrm{~m}$ above ground level. The Pukekohe data came from an Orchard 2000 weather station (Beresford and Spink 1992) at Crop \& Food Research, Cronin Road, Pukekohe. Canterbury surface wetness and rainfall data came from Orchard 2000 stations either between Lincoln and Rolleston or at Lincoln University, and temperature and relative humidity data came from the Crop \& Food Research meteorological site at Boundary Road. These three stations were within $4 \mathrm{~km}$ of each other on the Canterbury Plains. Correlations between dry bulb temperatures and rainfall among the Canterbury sites showed adequate agreement for the purposes of this study.

\section{RESULTS}

Sporulation-infection events potentially occurred in any month from SeptemberApril in both regions and there was no trend for particular months to have consistently greater numbers of events in either region (Figure 1). There was considerable variation among years and sites in numbers of events per month, but greater numbers occurred at Pukekohe, averaging $27-43 \%$ of days per month, than at Lincoln where the average was $10-18 \%$ of days per month. In 1993/94 Pukekohe had relatively few events and this was associated with abnormally low rainfall for South Auckland, with September, October, December and January all having less than half the long term average rainfall (Anon. 1983). 

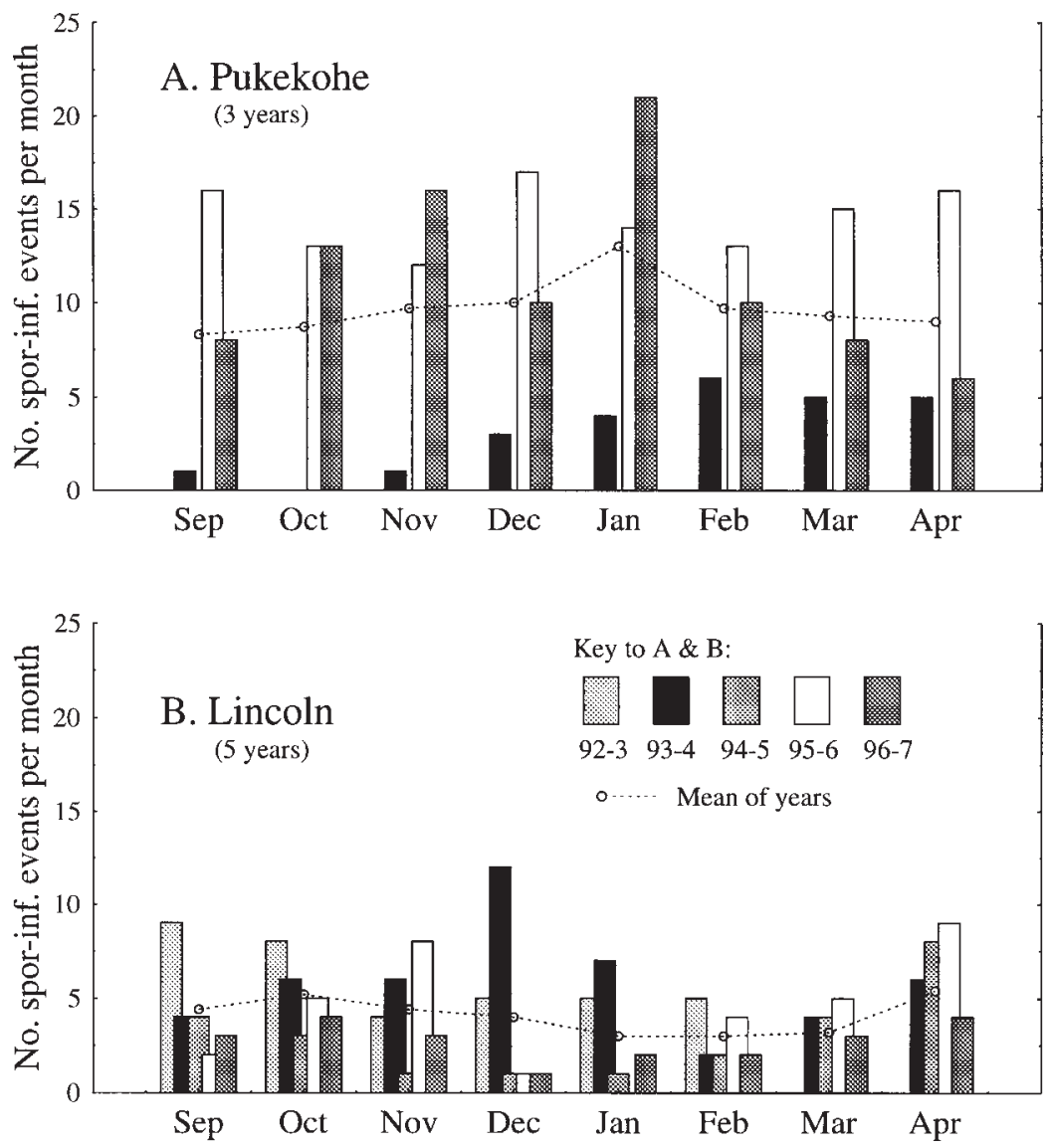

FIGURE 1: Numbers of days per month when onion downy mildew sporulationinfection events were predicted from historical weather records at Pukekohe in South Auckland (3 years) and Lincoln in Canterbury (5 years).

Of the five criteria that must be met for a sporulation-infection event to occur, the two temperature criteria, which affect sporulation, were almost never limiting. There was a relatively small percentage of days when rain during the high $\mathrm{RH}$ period limited sporulation, ranging from 3-29\% of days per month at Pukekohe and from 0-37\% of days per month at Lincoln. The factors most often limiting were $\mathrm{RH}$ (too low to allow sporulation) and morning or evening leaf wetness (duration too short to allow infection) (Table 1). At Lincoln, for the majority of months and years, low RH most often prevented sporulation-infection events occuring. In two out of the three years at Pukekohe, leaf wetness for infection was the most often limiting factor. However, in the dry 1993/94 season, RH limited sporulation, as occurred in Canterbury.

The occurrence of continuous periods when conditions were not suitable for sporulation and infection were used to compare sites and years for relative scope to modify fungicide use. Standard downy mildew fungicide programmes involve 
applications every 7-10 days to protect new emerging leaves from infection and to replace fungicide cover lost through weathering. It was assumed that the more often periods of six or more consecutive days without a sporulation-infection event occurred, the more possible it would be to reduce numbers of fungicide applications required during a season. Reductions in fungicide numbers would result from applying fewer curatives in response to infection periods and/or delaying the application of protectants during fine periods.

At Lincoln, 50-95\% of days which were unsuitable for sporulation and infection occurred in runs of 6 or more consecutive days. In contrast, at Pukekohe in 1995/96 and 1996-97, only 14-29\% of days unsuitable for sporulation and infection occurred in runs of 6 or more days. The dry 1993/94 season at Pukekohe was again more like Canterbury, with $80 \%$ of the days which were unsuitable for sporulation and infection occuring in runs of six or more days.

TABLE 1: Factors most often limiting the occurrence of potential sporulationinfection events. Numbers in brackets are the percentage of days per month when the indicated component was not fulfilled.

\begin{tabular}{lcllll}
\hline & $1992 / 1993$ & $1993 / 1994$ & $1994 / 1995$ & $1995 / 1996$ & $1996 / 1997$ \\
\hline $\begin{array}{l}\text { Pukekohe } \\
\text { September }\end{array}$ & - & & & & \\
October & - & RH (80) & - & Wetpm $^{2}(17)$ & RH (57) \\
November & - & RH (100) & - & Wetam $^{3}$ (52) & Wetpm (52) \\
December & - & RH (84) & - & Wetam (47) & Wetam (57) \\
January & - & RH (84) & - & Wetam (45) & Wetam (77) \\
February & - & RH (71) & - & Wetam (74) & Wetam (65) \\
March & - & RH (74) & - & Wetam (42) & RH (57) \\
April & - & RH (77) & - & Wetam (33) & RH (63) \\
& & & & & \\
Lincoln & & & & & \\
September & Wetpm (43) & RH (50) & RH (73) & RH (73) & RH (67) \\
October & RH (55) & RH (77) & RH (81) & RH (77) & RH (81) \\
November & RH (70) & RH (73) & RH (94) & Wetpm (60) & RH (83) \\
December & RH (81) & RH (58) & RH (97) & Wetam (77) & RH (94) \\
January & RH (77) & RH (77) & RH (94) & RH (94) & RH (87) \\
February & RH (75) & RH (71) & RH (86) & RH (82) & RH (89) \\
March & Wetam (100) & RH (71) & RH (84) & RH (81) & RH (77) \\
April & Wetam (100) & Wetam (67) & RH (70) & RH (47) & RH (80) \\
\hline
\end{tabular}

${ }^{1} \mathrm{RH}$ : Relative humidity for sporulation, $\geq 95 \%$ between 0100 and 0500 .

${ }^{2}$ Wetpm: Leaf wetness for three hours between 1900 to 2400 for infection during the night following that when sporulation occurred.

${ }^{3}$ Wetam: Leaf wetness for four hours between 0500 to 0800 for infection of deposited spores on the same night that sporulation occurred.

\section{DISCUSSION}

The severity of downy mildew in onion crops varies from year to year and variations in weather conditons are thought to be an important cause of this variability (Wright 1992). This weather-based study showed large variation in numbers of predicted sporulation-infection events between years and this is consistent with weather being a major determinant of variation in disease. Because disease observations were not available, it was not possible to relate variations in actual disease to variations in predicted risk. The study showed that although disease risk is generally greater in South Auckland than in Canterbury, low risk seasons can occur in South Auckland.

There appeared to be a relationship between the "drier" climate of Canterbury, as indicated by monthly rainfall, and a tendency for disease risk to be limited by 
insufficient RH in the early hours of the morning to allow sporulation. Under the higher rainfall normally associated with South Auckland, more infection periods occurred and their number tended to be limited by the duration of leaf wetness for infection of deposited spores. However, in South Auckland in one year (1993/94), the Canterbury pattern was observed.

Downy mildew usually appears in New Zealand onion crops in October or November and fungicide programmes against downy mildew generally begin between early and mid-October. Jesperson and Sutton (1987) suggested that the "Downcast" criteria could be used to initiate the fungicide programme at the time of the first sporulation-infection period. In this study conditions were conducive to disease at the beginning of September in both regions, more than one month before fungicide programmes normally begin. This suggests that either fungicide programmes should be initiated much earlier in New Zealand, or that the criteria overpredicted disease risk. Field trials investigating fungicide application timing are required to determine the optimum time to initiate fungicide programmes. Although the accuracy of the criteria has been tested in Canada (Hildebrand and Sutton 1984 a, b and c; Jesperson and Sutton 1987), their accuracy under New Zealand conditions needs to be evaluated in the field.

Forecasting criteria could be used to modify fungicide use for downy mildew by withholding a scheduled application when weather forecasts indicate infection conditions will not occur (Beresford et al. 1989), or by applying curative fungicides in response to infection events. There is greatest scope to achieve both of the above where few sporulation-infection events occur relative to the normal frequency of fungicide applications, and where long periods free of sporulation-infection events occur. Both of these conditions occur in drier regions such as Canterbury or in dry seasons in normally "wet" regions, such as 1993/94 in South Auckland.

This study represents a first step in developing disease forecasts to help the New Zealand onion industry improve the efficiency of pesticide use by allowing more precise fungicide timing. This may eventually lead to reductions in the numbers of fungicides applied in some seasons. The disease risk prediction approach should also help to alleviate consumer and grower concerns about prophylactic fungicide use and its potential to cause chemical residues in food, environmental contamination and adverse effects on human health.

\section{ACKNOWLEDGEMENTS}

Thanks are due to Warwick Henshall of HortResearch, Peter Jamieson of Crop \& Food Research and the NIWA National Climate Database for provision of meteorological data, and to Doug Grant of Crop \& Food Research, for information on downy mildew susceptibility of onion cultivars. This research was funded by The Foundation for Research Science and Technology.

\section{REFERENCES}

Anon., 1983. Summaries of climatological observations to 1980. N.Z. Met. Service Misc. Publication 177, 172 pp.

Beresford, R.M. and Spink, M., 1992. A national disease forecasting system for apple black spot (Venturia inaequalis) in New Zealand. Acta Horticulturae 313: 285296.

Beresford, R.M., Salinger, M.J., Bruce, P.E. and Brook, P.J., 1989. Frequency of infection periods for Venturia inaequalis in New Zealand and implications for fungicide use. Proc. 42nd N.Z. Weed and Pest Control Conf.: 159-164.

Jesperson, G.D. and Sutton, J.C., 1987. Evaluation of a forecaster for downy mildew of onion (Allium cepa L.). Crop Prot. 6: 95-103.

Hildebrand P.D. and Sutton J.C., 1982.Weather variables in relation to an epidemic of onion downy mildew. Phytopath. 72: 219-224.

Hildebrand P.D. and Sutton J.C., 1984a. Relationships of temperature, moisture and inoculum density to the infection cycle of Peronospora destructor. Can. J. Plant Path. 6: 127-134. 
Hildebrand P.D. and Sutton J.C., 1984b. Effects of weather variables on spore survival and infection of onion leaves by Peronospora destructor. Can. J. Plant Path. 6: 119-126.

Hildebrand P.D. and Sutton J.C., 1984c. Interactive effects of the dark period, humid period, temperature and light on sporulation of Peronospora detructor. Phytopath. 74: 1444-1449.

Wright, P.J., 1992. Downy mildew. Commercial Grower 47: 20. 